\title{
Measuring and Assessing Regional Education Inequalities in China under Changing Policy Regimes
}

\section{Lili Xiang ${ }^{1}$ D $\cdot$ John Stillwell $^{1} \cdot$ Luke Burns $^{1} \cdot$ Alison Heppenstall $^{1}$}

Received: 22 May 2018 / Accepted: 20 February 2019/

Published online: 6 March 2019

(C) The Author(s) 2019

\begin{abstract}
China's uneven regional economic development and decentralisation of its education system have led to increasing regional education disparities. Here, we introduce a new multidimensional index, the Index of Regional Education Advantage (IREA), underpinned by Amartya Sen's capability approach, to evaluate the effectiveness of policies targeted at reducing regional/provincial educational inequalities in China since 2005. The analysis of the distribution of IREA scores and the decomposition of the index reveals that education in north-eastern China is better than in the south-west part of the country, a pattern which lacks conformity with the eastern, middle and western macro-divisions adopted by Central Government as the basis of policy implementation. In addition, the education of migrant children and the low transfer rate into high schools are identified as key issues requiring Government attention.
\end{abstract}

Keywords Regional education inequalities · Index · Capability approach · Education policy $\cdot$ China

\section{Introduction}

Education equality has been valued in numerous international legal instruments and by leading worldwide development agencies (OECD 2012; UNESCO 2015). Equality in education matters not only because it can improve human capital production, but also because it offers the chance to promote fairness in other systems, like the economy (UNESCO 2002; Brighouse et al. 2010; Wilkinson and Pickett 2010; Baker et al. 2016). Education inequalities will exacerbate existing economic inequalities and be detrimental to long-term economic prosperity (Guo 2006; Holsinger and Jacob 2009; Shindo 2010). After 30 years of reform and the pursuit of an 'opening up' policy,

Lili Xiang

gylx@leeds.ac.uk; bnu_lili_xiang@163.com

1 School of Geography, University of Leeds, Woodhouse Lane, Leeds LS2 9JT, UK 
remarkable economic and social achievements have been made by China. However, the rapid economic development has been accompanied by intensifying inequalities, such as increasing provincial economic inequalities and widening gap between urban and rural areas (Zhang and Kanbur 2009; He et al. 2018). Although debates about policy were generated that reflect concern with unequal development (Wei 1999; Yang 2002; Kanbur and Zhang 2005; Fan and Sun 2008; Li and Wei 2010), most of the literature considers only regional economic inequality in China, and relatively little attention has been paid to regional education inequality.

As the Chinese education system attempts to meet the needs and aspirations of economic and social transition, education reform based on decentralisation was conducted, involving local governments assuming primary responsibility for education investment and administration (Thomas and Peng 2010). Due to the negative effects of decentralisation and the uneven regional economic development prevailing in China (Bardhan 2002; Yang 2002; Rodríguez-Pose and Ezcurra 2009), regional education disparities have increased (Tsang 1996). As a consequence, since 2003, several recentralisation policies aimed at reducing regional education inequalities have been implemented by Central Government, including the Law of Compulsory Education in 2006 and the National Medium and Long-term Educational Reform and Development Plan Outline (2010-20) (NMLERD) in 2010 (The State Council of China 2010; Sun 2012).

Accordingly, evaluation of these policies is needed to assess their success and to set policy in the future. However, there is a limited amount of published research on regional education inequality in China and most of this work has used a Gini index to measure inequality in terms of education attainment (Qian and Smyth 2008; Wang 2014). In this context, the Gini index is a score that reflects the extent of overall inequality within an area; however, a single score for a whole country (China) cannot distinguish the locations of disadvantaged and advantaged areas; different distributions of regional education inequality may get the same score, so it becomes impossible to accurately measure regional education inequality and identify disadvantaged areas with this Gini index. Moreover, education equality is a multidimensional issue, so the use of only one indicator (of attainment) may lead to limited results. Implementing a policy based on improper evaluation may cause detrimental effects on education development (Vaughan 2007). Thus, a composite index of education inequality, underpinned by Sen's capability approach, is proposed in this paper as a more robust measure of inequality that can be used to investigate temporal changes as well as geographical disparities at the regional (or provincial) scale in China.

This paper is structured in five sections. The next section sets the scene by reviewing previous and current education related policies with a focus on their influence on education equality; the following section introduces the methodology underpinning a new Index of Regional Education Advantage (IREA); the results of the analysis are reported in the fourth section whilst the fifth section discusses the effects of related policies and makes a series of policy suggestions. Conclusions are then drawn in the final section.

\section{Policy Background}

Since the open-door policy was launched in 1978, China has achieved unprecedented economic growth and vigorous urbanisation ( $\mathrm{Li}$ and Wei 2010; Chen et al. 2013). 
However, at the same time, due to the uneven development process, regional inequalities have intensified (Wei 1999; Yang 2002; Liu et al. 2014). In the early stage of economic reform, the China's strategies for regional development followed inverted-U and growth pole theories and the reform policies in 1980s were favourable to coastal areas (Wei 1999), where many special economic zones and economic open cities were established to attract foreign investment and trade. These coastal 'open cities' and special economic zones enjoyed great autonomy, superior tax incentives and privileged resource allocations. Although some interior cities also opened up from 1994, inland areas experienced significant disadvantage and were lagging far behind (Yang 2002; Kanbur and Zhang 2005). The widening regional development and income gaps led to massive population migration from inland areas to coastal areas (Liu and $\mathrm{Xu} 2017$ ).

Since the late 1990s, a series of policies and programmes were carried out by the Chinese Government to alleviate regional inequality and promote social and political stability, such as the Eleventh Five-Year Plan (2006-2010), which emphasises coordinated regional development (Fan and Sun 2008). In this context, state policies relating to the Chinese education system have also undergone considerable change in the last thirty years based on the different development stages that the country has experienced and the various objectives associated with each stage. These policies can be classified into two broad periods according to their main purpose.

\section{Financial and Administration Decentralisation, 1985-2005}

Education in China experienced particularly dramatic disruption in the chaotic social movement referred to as the Great Proletarian Cultural Revolution (1966-76) (Unger 1984). With the shift from a planned to a market oriented economy in the late 1970s and early 1980s, the importance of science and technology for economic transition and development was reiterated by the Chinese Government (Hannum et al. 2007; Huang et al. 2015). The Decision on the Reform of the Education System (DRES) made by the Central Committee of the Communist Party of China (Zhonggong zhongyang guanyu jiaoyu tizhi gaige de jueding) was issued in May, 1985. Its main aim was to produce a qualified labour force for promoting market reform and economic modernisation. The nine-year compulsory education framework was confirmed in the DRES and, in addition, the financial management and administration functions of the education system were to be decentralised so as to increase efficiency (Hannum et al. 2007). These measures were implemented through the Compulsory Education Law of the People's Republic of China in 1986 (Sun 2010).

After these reforms were introduced, management and financial responsibilities for education provision were transferred to local government. This meant that local governments were given the primary responsibility for providing most of the funding for schools, including investment in the construction or reconstruction of school buildings, education facilities, teachers' salaries, and all recurrent expenditures (Sun 2010). In rural areas, primary, middle and high schools were sponsored by local authorities in villages, townships and counties respectively, while primary and secondary education in urban areas was sponsored by district and municipal governments respectively (Tsang 1996; Sun 2010). For the above local governments, there were two main sources of public funds for education: budgetary allocation from local government and very limited categorical grants from higher levels of government (Tsang 1996). 
Central Government thus had almost no role in the financing of basic education under the new system (Hu 2012). In order to complement insufficient budgets, local authorities were allowed to collect education levies and surcharges as extra-budgetary funds to support education within the same locality. However, this tax income proved insufficient to cover the related education expenditure and was an unstable source of income. Therefore, schools needed to raise funds through different methods to meet expenditure. Schools raised extra money (known as 'non-budgeted item' or yusuanwai) both to pay for non-recurrent expenditure and to raise teachers' income through charging miscellaneous fees, running enterprises and receiving individual donations and generating income from school-run industries (Sun 2010; Huang et al. 2015). The diversification of sources of funding for education is a distinctive characteristic of this period. The mobilisation of non-government resources was broadened and intensified at school level. The extra-budgetary resources grew sharply and became increasingly important sources of funding for basic education (Tsang 1996). Gradually, education services became a valued commodity and access to education became increasingly linked to the consumers' ability to pay (Whitty 1997).

With the rapid growth of the economy, huge progress in education was also made after 1985 with $98.5 \%$ of the counties in China introducing the nine-year compulsory education system. Moreover, the conditions of school buildings, education equipment and teachers' qualifications were also improved dramatically (Tsang 2000). The policies in this period were successful in mobilising additional government and nongovernment resources but they also exposed significant inefficiencies and glaring inequalities. It became apparent that the decentralised administration and financial system was limiting the Central Government's ability to reduce regional disparities (Tsang 1996), and the allocation of resources for regional education services had been directly linked to their economic development (Zhu and Peyrache 2017). Therefore, due to the uneven regional economic development occurring in China in these years, different areas had varying abilities to invest in education (Zhang et al. 2012).

Given the continuing inadequacy of national investment in education, this situation led to certain areas becoming seriously disadvantaged. In poor rural areas, the weak tax base of local governments, meagre household incomes and an impotence to mobilise non-governmental resources imposed strong limits on the amount of budgetary and extra-budgetary funds that could be collected for basic education. Furthermore, as a result of the worsening financial circumstances in some areas, teachers' payments were delayed or stopped. As a consequence, poor and remote areas had very low enrolment and completion rates for basic education as well as higher proportions of dilapidated school buildings (Tsang 1996). In contrast, wealthier areas became capable of mobilising their affluent non-public resources to improve their education services. This situation increased regional education disparities and family educational expenditures (Hannum et al. 2007).

China's Central Government gradually realised the limitations of decentralisation and responded with a series of policies to promote education equity and expand access to education in disadvantaged areas. For example, from 2001 to 2005, the basic sources of funding for compulsory education have moved from township government to county government, which better assured educational expenditure, especially on teachers' pay in poor villages. However, there were still substantial impoverished counties with insufficient finance to supply adequate funds for education. Thus, education in 
undeveloped areas remained in the predicament of having a funding shortage and more policies were required to solve this problem after 2005 .

\section{Education Equality and Unified Planning at Provincial Level, after 2005}

The policies in the last ten years have attempted to reduce education inequalities among different groups and different regions by implementing some substantive measures. The five most important policies discussed in this research, in chronological order, are: (1) notification of the reform of the funding guarantee system for rural compulsory education (NR) (December 24, 2005); (2) the Compulsory Education Law of the People's Republic of China (June 29, 2006); (3) notifications of the State Council on exemption of tuition and miscellaneous fees for compulsory education in urban areas (NU) (August 12, 2008); (4) National Medium and Long-Term Educational Reform and Development Plan Outline (2010-20) (NMLERD) (July 29, 2010); and (5) notifications of further improvement of the funding guarantee system for urban and rural compulsory education (NUR) (November 25, 2015).

It is important to recognise that a macro-region division has frequently been used by the Chinese Government when implementing policies. Mainland China is divided into three economic zones: eastern (eleven provincial level units); central (eight provincial level units); and western (twelve provincial level units) (Fig. 1), based on their economic development level and geographic location (Li and Wei 2010). By adjusting the size of each province according to their per capita GDP (PCGDP), the inset cartogram (Fig. 1) displays the extent of economic inequality. The macro region with highest PCGDP is the eastern region, while the western region has the lowest PCGDP. The financial policies for education which will now be described are based on this spatial partitioning.

Since 2005, a new funding guarantee system of education has been gradually introduced that provincial level governments are required to make overall plans for the provision of education, and the role of county level governments has changed from providing funding to administering funding for education. In December 2005, NR was issued by the State Council (Table 1), indicating that all the rural areas in western China were exempt from tuition and miscellaneous fees from 2006, and all rural parts of central and eastern areas were exempt from these fees from 2007. In addition, the new policy stipulated that the basic standard for per pupil public funding in rural areas in each provincial level unit should be formulated by provincial level governments. Accordingly, the public funds for each pupil should not be lower than the amount of this basic standard. The funds for waiving tuition and miscellaneous fees and basic public funds for rural areas are shared by Central Government and local governments on the basis of the items and proportions as prescribed by the State Council: 80:20 for the west; 60:40 for central; the proportions for eastern provinces, except for municipalities directly under the control of Central Government, were determined by their financial position respectively. Central Government provides all the funds for free textbooks in western and central areas, whereas these fees are guaranteed by local governments in the eastern region. Building renovation expenses for all primary and middle schools in rural areas are jointly sponsored by Central Government and local government (50:50) for provincial level units in western and central areas, while these funds are provided entirely by local government 


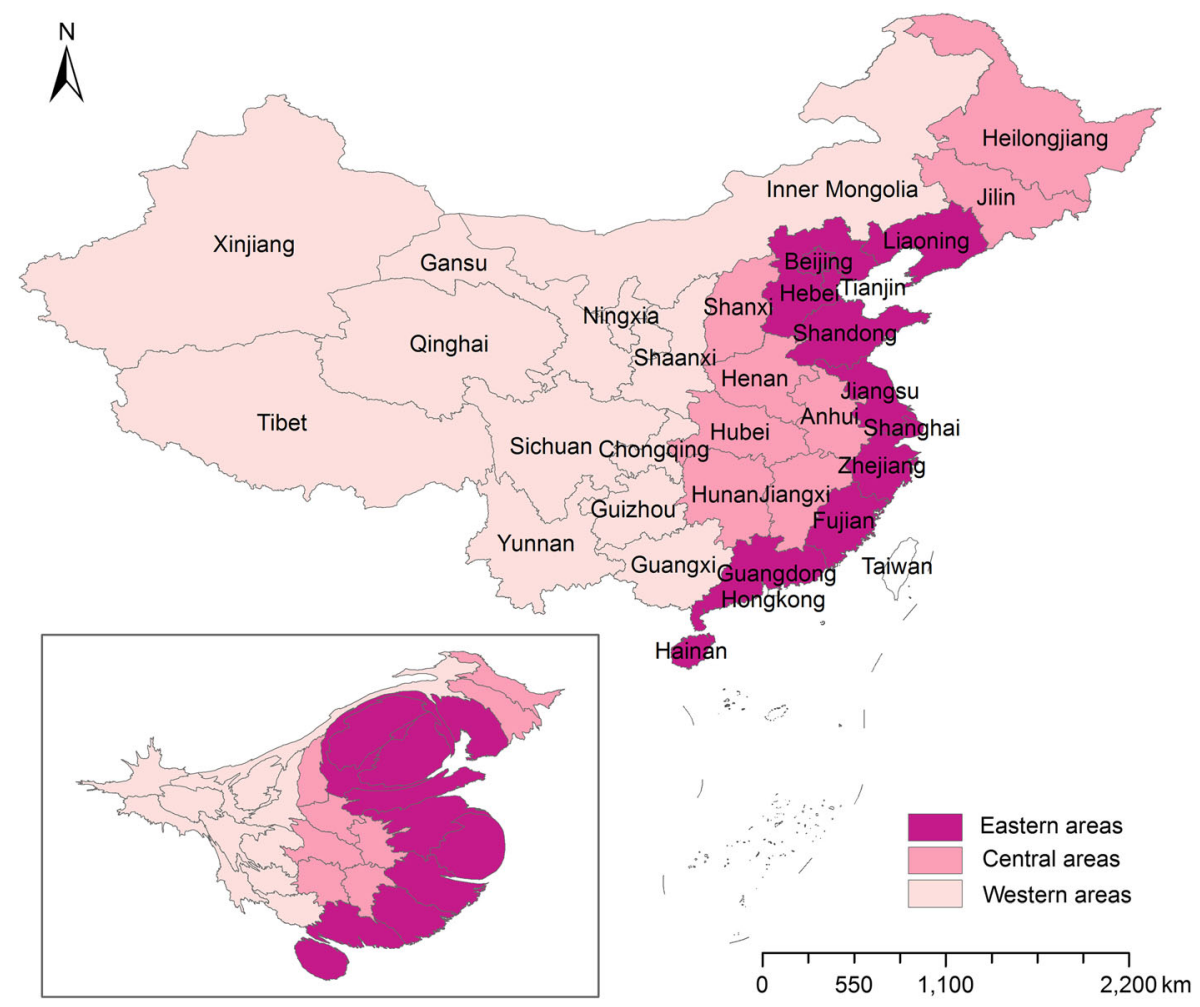

Fig. 1 Three macro-regions of China and cartogram inset with per capita GDP (2014) for provincial level units

in the eastern region. The provincial level governments should enhance the amount of transfer payments to ensure the salaries of teaching staff in rural areas.

Exemption from tuition and miscellaneous fees for compulsory education was confirmed by the Compulsory Education Law in July 2006 and therefore extended across the country as a whole (Standing Committee of the National People's Congress 2006a). It also stipulated that the funding for compulsory education should be fully guaranteed by public finances from national and local government to fundamentally solve the problem of insufficient educational funds. It also proclaimed that compulsory education should be administered by county or higher-level authorities. Each level of government should establish separate funding for compulsory education, and these funds should be equally distributed, except for the extra funds provided to rural areas and low-performance schools (Standing Committee of the National People's Congress 2006b).

It is clear that the principles emphasised by Central Government and imposed by law were to allocate education resources rationally, improve the education condition of disadvantaged areas and promote the balanced development of education. At the same time, the local authorities in urban areas were still responsible for providing funds for their own compulsory education and were only partly supplemented by Central Government through limited grants and transfer payments. Although the Compulsory Education Law had already claimed that no tuition or miscellaneous fees should be charged for provision of compulsory education, it had been applied to urban areas only after the release of NU in 2008 (Table 1) and the related funds were still solely provided by local (provincial level) government. 





From 2004 to 2010, the Government's educational budget (zhengfu yusuannei jiaoyu bokuan) increased from $£ 40.3$ billion $^{1}$ to $£ 134.9$ billion, an increase of $235 \%$ (Ministry of Education of PRC 2005, 2011). Moreover, the funds from Central Government increased from $£ 2.99$ billion to $£ 25.47$ billion, or 7.5 times (Ministry of Education of PRC 2011). Central Government improved its ability to reduce education inequalities and to support education in rural and western areas. Furthermore, the NMLERD Plan Outline was published in 2010 (The State Council of China 2010; Sun 2012). The word "equity" appears in the document 17 times (Hu 2012) and the text indicates that fairly large regional and rural-urban inequalities continue to exist (Sun 2012). More accessible and equitable education which benefits everyone was posited as the most important objective; the plan aims to achieve equal basic public education for everyone and to narrow disparities (Thomas and Peng 2010; Sun 2012).

In 2015, the NUR was issued to unify the funding guarantee system for compulsory education in urban and rural areas. The education expenditure proportions shared by Central Government and local governments are unified in this new policy, while in previous policies the Central Government mainly supported education in rural areas and local governments in urban areas had to take responsibility for the funds for their own compulsory education services. In addition, the basic standard for per pupil public funds per year were also unified: $£ 60$ for primary school pupils and $£ 80$ for middle school pupils from western and central areas; $£ 65$ for primary school pupils and $£ 85$ for middle school pupils in eastern areas. Specifically, the public funds are guaranteed by Central Government and local governments in the proportion 80:20 for western areas, 60:40 for central areas and 50:50 for eastern areas (Table 1).

All in all, it is clear from this synopsis of policy that Central Government has put more emphasis on promoting education equality by supporting disadvantaged groups and regions. However, before addressing the question of how policies have affected inequalities within the education system, it is necessary to accurately monitor the impact of policies that have been implemented already. In order to achieve these objectives, the evolution of regional education inequalities is evaluated in the following section using a new index.

\section{Index of Regional Education Advantage (IREA)}

In this section, a new multidimensional measure of nationwide education inequality that we call the Index of Regional Education Advantage (IREA) is introduced. Policy implementation based on improper evaluation may cause detrimental effects on education development (Vaughan 2007). Due to the narrowly defined focus (i.e., attainment) of conventional approaches, capability theory, proposed on the basis of criticisms of other human well-being evaluation approaches, was used to develop an alternative analysis framework. The proposed approach in our new index is more comprehensive in terms of the dimensions that are included and therefore is likely to provide a better measure and deeper understanding of regional education disparities.

\footnotetext{
$\overline{{ }^{1} \text { A conversion rate of } 10 \text { Chinese }}$ yuan to $£ 1$ is used in this research.
} 


\section{Capability Approach and its Application in Education}

Education is a key social factor among the non-economic dimensions that measure the well-being of an area (Jorda and Alonso 2017). In this research, Sen's capability approach, a normative framework for assessment and evaluation of well-being, social arrangements and policy design (Sen 1995; Sen 2001; Robeyns 2005) has been adopted as a theoretical framework to underpin our index. As Sen only sets out a general framework and deliberately leaves the capability component under-specified (Walker 2005), this approach requires further adaptation to the specific context.

Capability refers to the ability or level of freedom of an individual to choose or achieve something that he/she has reason to value being or doing (Walker 2005). In terms of education, children are not yet mature enough to make their own choices, so their freedom is constrained by compulsory education and the freedom considered here is more about the level of freedom they will have in the future (Saito 2003), given that education is crucial for them to develop other relevant capabilities. Agency is also one of the central concepts of the capability approach, referring to responsible individuals or groups who make their own choices and shape their own valued lives (Walker and Unterhalter 2007). In this research, the capability approach has been applied in the context of education within a region and thus all the people within that region are taken as one agent; in other words, this research looks at the average capabilities within each region (Robeyns 2005).

'Functioning' is the other core concept in Sen's approach. This refers to the achieved outcomes of education. Previous education inequality evaluation has usually focused on achieved outcomes, i.e., the functioning of systems, measured by educational attainment (Sen 1995; Qian and Smyth 2008; Lopez-Acevedo 2009; Tomul 2009). Average years of schooling has been frequently used as a proxy for educational attainment by researchers (Qian and Smyth 2008; Herrero et al. 2012) and organisations like the World Bank and UNESCO. However, evaluating only attainment outcomes or functioning provides little information about the process and context. There may be different stories lying behind equal achievement; however, the underpinning differences are germane to the discussion of equality and policy implications (Terzi 2007). The capability approach emphasises the potential to achieve functioning which requires us to evaluate the current functioning but also the opportunities and real freedoms available to achieve what people value (Walker and Unterhalter 2007).

Resource-based approaches are also frequently used in education disparity assessment; these consider the individual or group being equally well off when they have same amount of resources (Sen 1995) and are defined without considering the substantial variation in the ability to achieve conversion from capability into functioning across individuals and societies (Koo and Lee 2015). Individuals or groups may achieve different levels of functioning with the same resources. In contrast, the capability approach looks not only at the resources people have at their disposal but also the freedom to achieve the functioning combinations they value (Sen 2001).

Due to the deficiencies of existing simplistic measures, this research presents a new analytic framework for education in China based on Sen's capability approach (Fig. 2). The proposed framework that we use for regional education disparity involves three dimensions: enrolment, attainment and provision, each of which is influenced by social context, including education policies, the environment and social norms. The achieved 


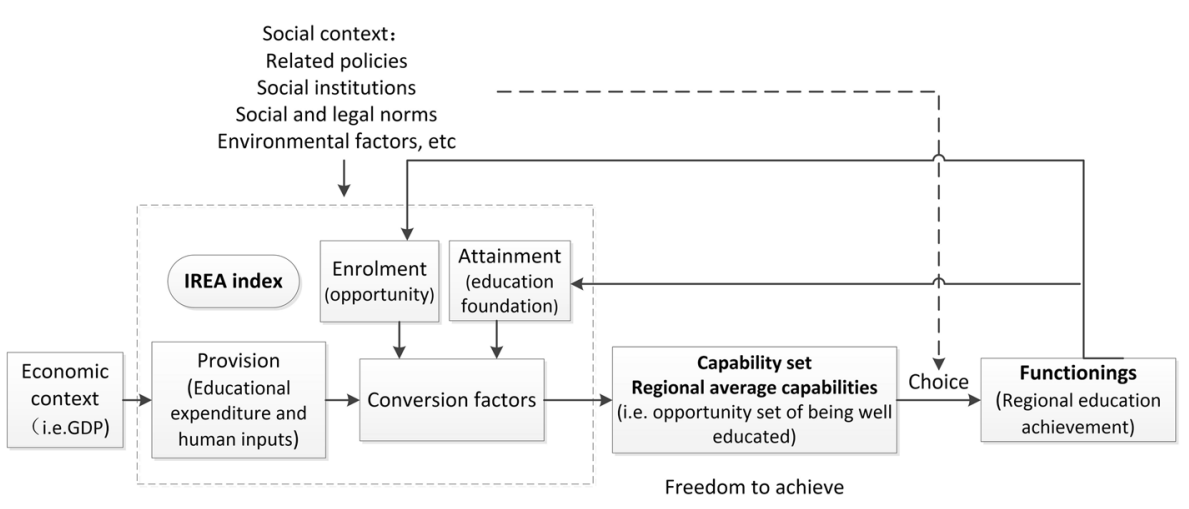

Fig. 2 The theoretical framework for the IREA index, adapted from Robeyns (2005)

educational attainment and enrolment rates work as the conversion factors. The enrolment rate indicates the available opportunity for children to participate in education, as only enrolled children have the chance to be well educated. Attainment refers to the current outcome (functioning of the past) and the educational foundation which will influence the ability of a region to convert resources into functionings in the future (future education attainment). Education provision indicates the availability of educational resources (schools, teachers, et cetera), which are normally related to regional economic context (i.e., per capita GDP), and their quality and degree of sufficiency will influence the capability to achieve functionings. In addition, the social norms and traditions that form people's preferences within a region will consequently influence their aspirations and effective choices. The achieved functionings in turn will influence, through feedback, the region's future resource conversion and capability. The capability approach of Sen, therefore, offers the theoretical justification for a comprehensive and multi-dimensional method to evaluate real regional education advantages or disadvantages. This assessment framework fills the current theoretical void and provides a basis for inequality measurements using the new synthetic index.

\section{Input Data}

The IREA has been created specifically to enable comparison of the characteristics of education found in different regions for different years. This is to reflect the development of education across China and the way in which educational inequalities have evolved before and after the introduction of new policies since 2005. IREA scores for 2004, 2009 and 2014 were calculated in this research. The year 2004 was selected as a reference year and the analysis of data for 2009 and 2014 enables an evaluation of the effectiveness of the related policies and provides a background for the implementation of NMLERD (2010) and NUR (2015).

IREA combines 17 education-related variables (Table 2), each of which is related to one of three facets of education enrolment, attainment and provision in a single score that quantifies the extent of education inequality between different provinces in China. The availability, compatibility and applicability of data have been considered and all the input data are data from Educational Statistics Yearbook of China and China 
Table 2 The indicators for the three facets of education inequality at the provincial level

\begin{tabular}{|c|c|c|c|}
\hline Facets & No. & Data / Indicators & Influence on education \\
\hline \multirow[t]{3}{*}{ Enrolment } & 1 & Net enrolment ratio for primary school & \multirow[t]{3}{*}{ Education opportunity } \\
\hline & 2 & Primary to middle school pupil transfer rate & \\
\hline & 3 & Middle to high school pupil transfer rate & \\
\hline \multirow[t]{2}{*}{ Attainment } & 4 & Literacy rate & \multirow{2}{*}{$\begin{array}{l}\text { Current foundation for } \\
\text { education development }\end{array}$} \\
\hline & 5 & Average years of schooling & \\
\hline \multirow[t]{12}{*}{ Provision } & 6 & Teacher-pupil ratio for primary school & \multirow{12}{*}{$\begin{array}{l}\text { Quantity and quality of } \\
\text { education provision }\end{array}$} \\
\hline & 7 & Teacher-pupil ratio for middle school & \\
\hline & 8 & Teacher-pupil ratio for high school & \\
\hline & 9 & $\begin{array}{l}\text { Proportion of teachers' attainment is equal and } \\
\text { above associate bachelor for primary school }\end{array}$ & \\
\hline & 10 & $\begin{array}{l}\text { Proportion of teachers with higher professional } \\
\text { title for primary school }\end{array}$ & \\
\hline & 11 & $\begin{array}{l}\text { Proportion of teachers' attainment is equal and } \\
\text { above undergraduate for middle school }\end{array}$ & \\
\hline & 12 & $\begin{array}{l}\text { Proportion of teachers with higher professional } \\
\text { title for middle school }\end{array}$ & \\
\hline & 13 & $\begin{array}{l}\text { Proportion of teachers' attainment is equal and } \\
\text { above undergraduate for high school }\end{array}$ & \\
\hline & 14 & $\begin{array}{l}\text { Proportion of teachers with higher professional } \\
\text { title for high school }\end{array}$ & \\
\hline & 15 & Per-pupil educational expenditure of primary school & \\
\hline & 16 & Per-pupil educational expenditure of middle school & \\
\hline & 17 & Per-pupil educational expenditure of high school & \\
\hline
\end{tabular}

Educational Finance Statistical Yearbook that relate to geographical provinces in China. In this case, data from Statistics Yearbooks are better than data from the decennial census, since only 2000 and 2010 census data are available. In addition, most of the variables follow the official definitions (Ministry of Education of the People's Republic of China 2015) and measure education in the same direction such that a higher score for each indicator represents a preferable situation.

As each variable has a different measurement unit, standardisation is required to convert the indicators into a common metric to allow aggregation (OECD 2008). The most commonly used methods, z-score and max-min standardisation, are problematic. The z-score is not suitable because all the values needed for the later analysis should be positive, and the max-min method will arbitrarily increase the variance of some variables (Herrero et al. 2012) (e.g., net enrolment rate for primary schools). An alternative method, the distance to a reference for area $i, I_{i}$, is proposed for use in this study, and defined as:

$$
I_{i}=\frac{x_{i}}{x^{*}}
$$

where $x_{i}$ is the value of a variable $x$ for area $i$ and $x^{*}$ is a reference value for all areas. This standardisation process only defines the units for measuring variables. In order to 
enable the index to be comparable across years, the mean of 2009 was used as the common reference values for all three years. Once standardisation has been undertaken, the data are ready for aggregation in the next step.

\section{Weighting and Aggregation}

As the IREA is a composite summary measure, it is often desirable to assign weights to indicators based on their perceived importance (Jiang and Shen 2013). In addition, the IREA adopts a hierarchical indicator system so the score of each facet should be obtained before calculating the final composite score. There are several approaches that can be used to determine the weights of indicators, such as equal or arbitrary weights, expert opinion weights, Principal Components Analysis (PCA) and factor analysis (Decancq and Lugo 2013). Whilst all methods have their advantages as well as disadvantages, the decision about which method to adopt depends on the research purpose, the data type and the data characteristics (Deutsch and Silber 2005). We have used different weighting and aggregation methods for assigning weights to each of the facets and indicators.

The three variables for measuring enrolment (Table 2) are not independent and not perfectly substitutable; for example, the enrolment in primary schools will influence the volume of students transferring from primary school to middle school. The geometric mean is therefore used to obtain the enrolment score.

The weights for the two indicators of attainment are determined according to the principle of frequency-based weights (Deutsch and Silber 2005; Decancq and Lugo 2013). The indicators which are weak in reflecting education differences should be given relatively lower weights. As the literacy rate is already very high and average years of schooling (AYS) has been emphasised in previous research (Qian and Smyth 2008), a weighting of 1 was given to the literacy rate, while a weight of 2 was assigned to AYS.

Weightings, which represent relatively subjective approaches, proved difficult to establish for the final facet, provision of education, where the assessment involves a large number of indicators (twelve variables); therefore a more objective, mathematical approach, PCA, was considered since it is a useful statistical technique to simplify a large set of multidimensional variables and was originally designed as a dimensionreducing technique (Jiang and Shen 2013; Pan et al. 2017). It avoids arbitrariness (Pan et al. 2017) and can also take into account the (multi)collinearity between variables, the so-called double counting problem (Decancq and Lugo 2013). For the purpose of weighting, a commonly used approach is factor loading of the first component to weight the indicators related to education provision (Jiang and Shen 2013). The indicators with more unequal distributions will be assigned higher weights in PCA, while the ones with low standard deviations would be given lower weights (Vyas and Kumaranayake 2006).

After acquiring the scores for three facets, the enrolment and attainment scores were combined to produce a score for conversion factors with a weight of $1: 2$, given that attainment represents educational grounding for a region and is a more important conversion factor. According to the theoretical discussion, the conversion factors will influence the agents' capability to achieve valued functioning with given education provision, and will jointly affect the results. Thus, the IREA score was acquired by 
calculating the geometric mean of the scores of the provision and conversion factors. This fits with the theoretical framework and, in addition, it avoids the perfect substitutability feature of the arithmetic mean and penalises the dispersion of the variables that are aggregated. The marginal utility of an increase would be much higher for the variable with a lower score; thus, this geometric aggregation method provides a greater incentive for policy makers to address the problems within facets with low scores (OECD 2008; Herrero et al. 2012). This composite index provides a numeric measure that represents the magnitude of educational advantage or disadvantage and is useful in helping to formulate appropriate policy agendas.

\section{Analysis of Results}

Overall IREA scores have been calculated by ranking all areas by the value of their IREA across all the three years and then dividing the rank order into categories of equal class interval, so that quintiles are produced allowing comparison over time (Fig. $3 \mathrm{a}, \mathrm{b}$ and c). Thus, from 2004 to 2014, if a province's IREA changed quintile, this can be interpreted as the conditions of education having worsened or improved (Norman and

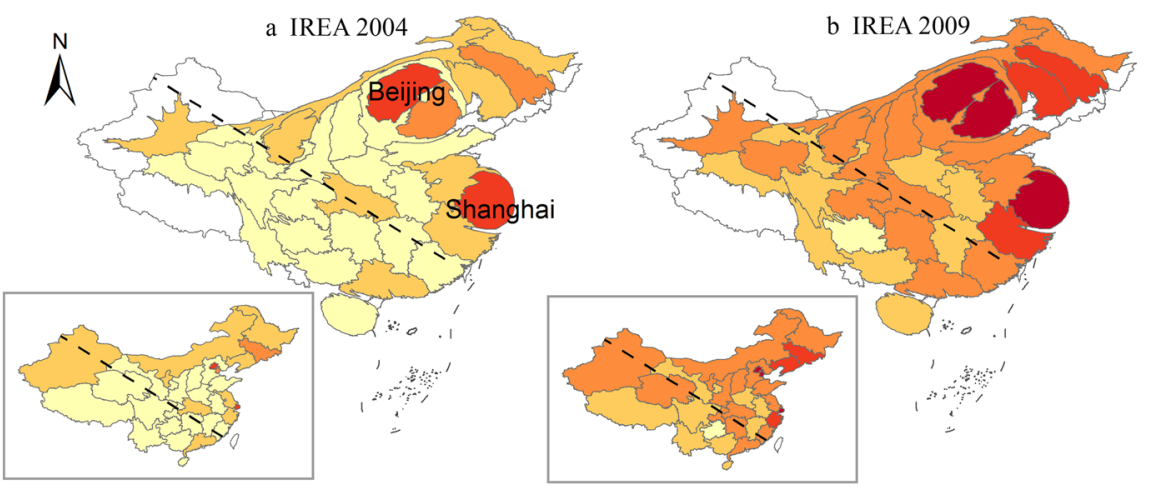

c IREA 2014
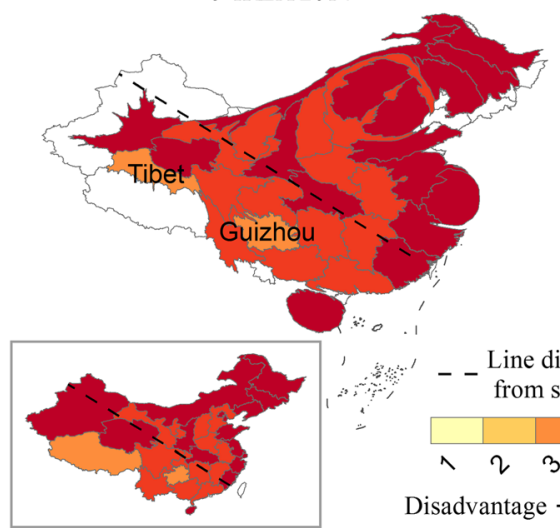

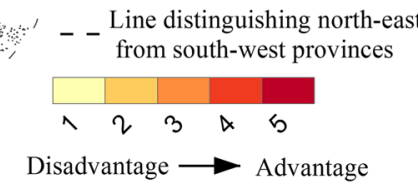

d IREA improvement 2004-2014

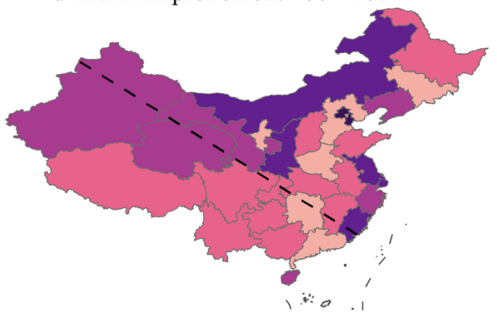

Fig. 3 IREA quintile distribution by provincial level units, 2004, 2009 and 2014 
Darlington-Pollock 2018). Quintiles 1-5 cover the range from lowest to highest scores. The spatial patterns of IREA scores across the three years display the overall regional educational inequalities and their evolution. The IREA was also decomposed into the scores for different facets to reveal the detailed variations and rationale behind the regional education disparities.

\section{Spatial Patterns of IREA}

Unlike previous regional educational studies which all focus on the coast-inland education dichotomy in China (Qian and Smyth 2008) or inequalities among the regional divisions, a different spatial pattern is apparent. Using the macro division between the north-east and south-west provinces shown by the dotted line shown in Fig. 3, the IREA scores of the north-east provinces are significantly higher than those of the south-west provinces, although the specific distributions have changed over time. The dotted line has been shown in Figs. 3 and 4 to indicate the overall regional education inequality pattern. The inequalities are more distinctly exhibited in the cartograms, in which the size of each region is adjusted according to its IREA value. In 2004 (Fig. 3 a), the IREA scores for Shanghai and Beijing were significantly higher than all other areas and most of the south-west provinces were in the worst quintile. In 2009 (Fig. 3 b), the distribution appears different, but in reality, the advantaged areas were still the north-east provinces, while the comparatively disadvantaged areas were located in the south-west. The distribution in 2014 (Fig. 3 c) is also consistent with this pattern. Thus, most provinces to the north-east of the dotted line have education advantages; the education conditions in provinces on this line are mixed and intermediate; the educationally disadvantaged provinces are concentrated to the south-west of this line. Figure $3 \mathrm{~d}$ shows the improvement of IREA for each province during the period from 2004 to 2014. We can observe that the improvement of western areas, especially the northern part, has been dramatic. Education in the eastern coastal areas also has developed considerably, while the development of south and middle areas has been comparatively slow.

\section{Decomposition of the IREA}

The IREA is a synthetic score which comprehensively reflects the condition of regional education inequalities. However, a single score conceals information and detailed variations between different component facets. In order to reveal the potential processes and detailed variations behind this index, the IREA was decomposed into its three component parts (Fig. 4).

In 2004 (before the relevant policies had been implemented), attainment, which is the achieved function of a previous stage, showed variations between eastern and western areas. For enrolment, the scores of the provinces to the north-east of the dotted line are relatively better. In addition, the provision scores of southern provinces were lower than those of the northern and coastal ones. Beijing and Shanghai had comparatively high scores for the three facets in 2004. The educational resources provided will be converted into the regions' capability under the influence of the conversion factors, enrolment and attainment. Accordingly, in 2004, some of the northern and coastal provincial level units have a higher capability (IREA score) to achieve better education in the future. 




Fig. 4 Cartograms for enrolment, attainment and provision by provincial level units, 2004, 2009 and 2014

Consequently, education attainment in 2009 displays a pattern of differentiation between north-east and south-west China. In addition, the enrolment score shows a clear north-east versus south-west pattern. At this stage, there is more financial investment from Central Government devoted to support education in the western areas. Education provision in the northern, eastern and part of the western areas is higher than the remaining areas. Accordingly, the IREA score, which measures the capability, also shows a north-east and south-west gradient.

From 2004 to 2014, the attainment level improved countrywide and the spatial pattern gradually changed from variations between eastern and western regions to differentiations between north-east and south-west areas. In 2014, the enrolment rates in most areas along the dotted line and to the north-east improved and moved into the fourth or fifth quintiles. However, it worth mentioning that the enrolment scores of Beijing and Shanghai experienced decline from 2004 to 2014. As the western areas acquired more support from Central Government, the pattern of education provision changed such that middle and southern areas became neglected and showed lower provision scores.

In addition, in 2014, in the northern areas where there were more support from Central Government and a solid education foundation, and in the eastern coastal areas with their higher economic development levels, the capability of education (IREA) was higher, indicating that these areas will have more chance of being advantaged, while the 
south-west provinces, especially Tibet and Guizhou, will remain disadvantaged in education in future. Therefore, it is likely that education inequalities between the south-western and north-eastern areas will continue in the near future, if the relevant policies remain unchanged.

\section{Discussion}

From the above analysis, we can conclude that basic primary school, middle school and high school education in China experienced considerable development over the ten year period. However, although Central Government has played an increasingly important role in promoting the development of education and in reducing education inequalities, there are still very dramatic regional education disparities and its spatial pattern has not really changed very much. With the help of the IREA index and its decomposition, particular problems underlying the current educational policies have been identified and discussed in the following sub-sections.

\section{Spatial Pattern of IREA and Area Partitioning of Policy Implementation}

It is not reasonable to implement education policies, especially the fiscal policies like NR, based on dividing China into eastern, central and western regions (Fig. 1) to promote education equality. The education-related policies should be implemented based on the evaluation of education-related indicators, whereas this division is based on economic development levels and natural environmental conditions. Thus, the new IREA which was developed based on direct indicators of education can better capture the differences in education development for each province across a number of facets. However, both the pattern of IREA and its decomposed facets at provincial scale do not match with the regional division adopted by Central Government. Furthermore, even economic development, measured by GDP per capita (the inset cartogram of Fig. 1), cannot be generalised and fully revealed by this rough partition. Undeniably, this regional division is helpful to clearly define the fiscal responsibilities of Central Government and local governments and acknowledge the increased educational investment in some less developed areas; however, education inequalities vary spatially and temporally, and it is not reasonable to set policies without considering the variations and their different development trajectories. This will decrease the effectiveness of these policies in reducing provincial level and rural-urban disparities in education and cause a waste of education funds to some extent. Unfortunately, the newly issued policies of NUR in 2015 are still based on this problematic regional division.

Moreover, the decomposition of the IREA index and examination its indicators enable us to explain the final composite IREA score and scores for three facets in each provincial level unit and to accurately identify other issues which hinder the efficiencies of policies in reducing regional education disparities.

\section{High School Education Lagging behind}

Education-related policies should also take the specific development level of each education stage into consideration. The component indicators reveal that the spatial 
variations in enrolment in compulsory education are small in 2014 (with the minimum 98.5\%), however, the provincial differentiation in middle to high school transfer rates was very substantial in 2014, with the lowest value of $43.9 \%$ (Tibet) and highest value of $68.8 \%$ (Tianjin), the latter value being 1.5 times the former. As high school education is the bridge between compulsory education and higher education, the comparatively lower transfer rate for high schools will be detrimental for high quality human capital accumulation and lead to further economic disadvantage in these already disadvantaged areas. The apparent spatial variations in the middle to high school transfer rate occur arguably because of the lower percentage of education investment by Central Government in high school education. At present, compulsory education has acquired more policy attention, such as NR and NUR, but Central Government has paid little attention to high school education. The Pearson correlation coefficient of education expenditure per pupil for high school education and the per capita GDP increased from 0.94 to 0.95 , which indicates the education investment in high school education in each province is thus still highly related to its economic development. Since the current popularisation of compulsory education, more emphasis should be put on supporting high school education development in less developed areas and the financial burden on families and local government should be reduced. Furthermore, more policies should be implemented to increase the availability of high school education for migrant children, while most emphasis by government at present has been on helping the children of migrants receive compulsory education locally.

\section{Education of Child Migrants}

Maps a and $\mathrm{c}$ in Fig. 4 illustrate that the enrolment scores of Beijing and Shanghai decreased over the ten year period. This was due to falling transfer rates from primary to middle school and from middle to high school, most likely to have been caused by the strict limitations on the migrants in these areas, i.e., migrants cannot enter local high schools. Migrants' children are thus forced to go back to their hometowns to receive middle and high school education. Before 2015, only education in rural areas was supported by Central Government, which has not been adapted to the situation of current rapid urbanisation and large-scale population movements. In 2014, migrant workers' children accounted for more than $25 \%$ of all primary school pupils and nearly $23 \%$ of all middle school pupils (calculated using data from the China Statistical Yearbook in 2015). Providing education to substantial numbers of migrants from rural areas will largely increase the financial burden on urban governments; therefore urban authorities usually display a negative attitude to offering equal education to migrants' children. Quality education is not really available for migrant children ( $\mathrm{Li}$ and Placier 2015; Xiang et al. 2018).

In order to meet the requirement of the people-oriented urbanisation proposed by Premier Li Keqiang in 2014, which is aimed at helping migrants to settle down in cities and ensuring that they enjoy the same public services, including education (Chen et al. 2018, 2019), more Central Government policies are needed to guarantee migrant children's right to access the same educational services. The NUR in 2015 unified the share of Central Government's support via urban and rural education expenditure for compulsory education. This policy will, to some extent, reduce urban governments' fiscal pressure on offering compulsory education to child migrants. However, high 
school education and all teachers' salaries are still solely sponsored by local government. Moreover, it worthy of note that the proportion shared by local governments and Central Government still varies by the regional division. A higher proportion of education expenditure is still shared by local governments in eastern areas, which are the main target areas for migrants (Liu et al. 2014; Liu and Xu 2017).

\section{Education in the Tibet Autonomous Region}

The framework of the capability approach also helps us to explain why attainment falls short in some regions, despite the increased resources that have been allocated. Take Tibet as an example. Although an improvement of education in Tibet has taken place and its education provision has increased very rapidly in the last ten years (the education expenditure per pupil for primary schools in Tibet is $£ 1661$, twice as much as the national average of $£ 840$ in 2014), education in Tibet is still worse than other provincial units, especially in terms of the enrolment rate and attainment (for example, the AYS is only 3.8, while the national average is 7.9). Except for its historically low enrolment and attainment, Tibet's ability to convert educational resources into capability (Fig. 2) has been influenced by its different context, including its natural physical condition and social environment. In 2004, the average population in Tibet was 2.6 persons per square kilometre and about $80 \%$ of residents lived in rural and nomadic livestock breeding areas (Postiglione et al. 2011). The service radius of primary schools in rural areas is around 15 to $20 \mathrm{~km}$, and the situation is even worse for nomadic areas, reaching up to 100 to $150 \mathrm{~km}$ (Postiglione 2009). In addition, educational progress is hampered by parents' cultural perspective on education (Postiglione et al. 2011). Some parents, especially those living in nomadic livestock breeding areas, are not willing to provide financial support for their children's schooling, because they have not recognised the long-term value of education and the curriculum that children are taught in school can be vastly different from their experiences in everyday life. Moreover, as a result of the influence of religion, some of the children have unfavourable attitudes to education if education content is incompatible with their own culture. (Gyatso et al. 2005; Postiglione et al. 2011).

\section{Conclusions}

A multidimensional index, the IREA, has been proposed and implemented in this paper to evaluate the effectiveness of policies targeted at reducing regional educational inequalities in China since 2005. This is the first time that such a task has been achieved. Education equality has been conceptualised by adapting Sen's capability approach which provides theoretical justification for the measurement of educational disparities and fills the current theoretical void for education inequality measurements. The patterns of the IREA and its component facets display a different 'way of looking' at education inequalities in China. Education in the north-east areas appears better than in the south-west parts of China, which is different from the area division adopted by Central Government as the base of policy implementation. In addition, the temporal comparison $(2004,2009$ and 2014) of the IREA helps us to explain how the pattern of education inequalities has evolved over time. Furthermore, key issues such as 
the equal education of child migrants and the obvious regional variation within high school education have been highlighted and some suggestions for improvement have been proposed.

Within a wider context, our evidence from China in terms of education inequalities not only sheds new light on the debate over the impact of fiscal decentralisation and centralisation on educational resources redistribution, but also contributes to understanding the role of institutions in determining equal educational distributions among regions and different groups of people. The discussions of China's policies for reducing regional education inequality provide an alternative model specification, offer reference to the research of other regional capability sets and can fit into different contexts to facilitate research on regional development. As the policies referred to are not only aimed at reducing regional education variations but also narrowing the education gap between urban and rural areas, there is considerable potential for future studies of urban and rural education inequalities in China and the policies which have influenced their development.

Acknowledgements The lead author is grateful for funding from the Chinese Scholarship Council and the University of Leeds. Many thanks to Professor Adrian Favell for providing valuable suggestions and helpful comments to improve this paper.

Funding Chinese Scholarship Council and the University of Leeds.

\section{Compliance with Ethical Standards}

Conflict of Interest Statement We confirm that this work is original and has not been published elsewhere, nor is it currently under consideration for publication elsewhere. The authors declare that they have no conflict of interest.

Open Access This article is distributed under the terms of the Creative Commons Attribution 4.0 International License (http://creativecommons.org/licenses/by/4.0/), which permits unrestricted use, distribution, and reproduction in any medium, provided you give appropriate credit to the original author(s) and the source, provide a link to the Creative Commons license, and indicate if changes were made.

Publisher's Note Springer Nature remains neutral with regard to jurisdictional claims in published maps and institutional affiliations.

\section{References}

Baker, J., Lynch, K., Cantillon, S., \& Walsh, J. (2016). Equality and education. In J. Baker, K. Lynch, S. Cantillon, \& J. Walsh (Eds.), Equality: From Theory to Action (pp. 140-168). Hampshire: Springer.

Bardhan, P. (2002). Decentralization of governance and development. The Journal of Economic Perspectives, 16(4), 185-205.

Brighouse, H., Howe, K. R., Tooley, J., \& Haydon, G. (2010). Educational Equality (2nd ed.). London: Continuum.

Chen, M., Liu, W., \& Tao, X. (2013). Evolution and assessment on China's urbanization 1960-2010: Underurbanization or over-urbanization? Habitat International, 38, 25-33.

Chen, M., Liu, W., Lu, D., Chen, H., \& Ye, C. (2018). Progress of China's new-type urbanization construction since 2014: A preliminary assessment. Cities., 78, 180-193.

Chen, M., Gong, Y., Lu, D., \& Ye, C. (2019). Build a people-oriented urbanization: China's new-type urbanization dream and Anhui model. Land Use Policy, 80, 1-9. 
Decancq, K., \& Lugo, M. A. (2013). Weights in multidimensional indices of wellbeing: An overview. Econometric Reviews, 32(1), 7-34.

Deutsch, J., \& Silber, J. (2005). Measuring multidimensional poverty: An emprical comparision of various approaches. Review of Income and Wealth, 51(1), 145-174.

Fan, C. C., \& Sun, M. (2008). Regional inequality in China, 1978-2006. Eurasian Geography and Economics, 49(1), 1-18.

Guo, G. (2006). Decentralized education spending and regional disparities: Evidence from Chinese counties 1997-2001. Journal of Chinese Political Science, 11(2), 45-60.

Gyatso, S., Postiglione, G. A., \& Jiao, B. (2005). Education in rural Tibet: Development, problems and adaptations. China: An International Journal, 3(1), 1-23.

Hannum, E., Park, A., \& Cheng, K.-M. (2007). Introducation: Market reforms and educational opportunity in China. In A. Park \& E. Hannum (Eds.), Education and Reform in China (pp. 1-24). London: Routledge.

He, S., Chung, C. K. L., Bayrak, M. M., \& Wang, W. (2018). Administrative boundary changes and regional inequality in provincial China. Applied Spatial Analysis and Policy, 11(1), 103-120.

Herrero, C., Martínez, R., \& Villar, A. (2012). A newer human development index. Journal of Human Development and Capabilities, 13(2), 247-268.

Holsinger, D. B., \& Jacob, W. J. (2009). Inequality in Education: Comparative and International Perspectives. Hong Kong: Springer Science \& Business Media.

Hu, W. (2012). Thirty years of education in China: Between change and no change. Chinese Education \& Society, 45(1), 84-94.

Huang, Z., Wang, T., \& Li, X. (2015). The political dynamics of educational changes in China. Policy Futures in Education, 14(1), $24-41$.

Jiang, Y. H., \& Shen, J. F. (2013). Weighting for what? A comparison of two weighting methods for measuring urban competitiveness. Habitat International, 38, 167-174.

Jorda, V., \& Alonso, J. M. (2017). New estimates on educational attainment using a continuous approach (1970-2010). World Development, 90, 281-293.

Kanbur, R., \& Zhang, X. (2005). Fifty years of regional inequality in China: A journey through central planning, reform, and openness. Review of Development Economics, 9(1), 87-106.

Koo, J., \& Lee, H. (2015). Regional capability and regional disparity: A conceptual framework and applications within Korea. International Review of Public Administration, 20(2), 121-135.

Li, N., \& Placier, P. (2015). Migrant and non-migrant families in Chengdu, China: Segregated lives, segregated schools. Social Sciences, 4(2), 339-360.

Li, Y., \& Wei, Y. H. D. (2010). The spatial-temporal hierarchy of regional inequality of China. Applied Geography, 30(3), 303-316.

Liu, Y., \& Xu, W. (2017). Destination choices of permanent and temporary migrants in China, 1985-2005. Population, Space and Place, 23(1).

Liu, Y., Stillwell, J., Shen, J., \& Daras, K. (2014). Interprovincial migration, regional development and state policy in China, 1985-2010. Applied Spatial Analysis and Policy, 7(1), 47-70.

Lopez-Acevedo, G. (2009). 18. Mexico: Evolution of education and inequality in the last two decades. In D. B. Holsinger \& W. J. Jacob (Eds.), Inequality in Education: Comparative and International Perspectives (pp. 417-443). Hong Kong: Springer Science \& Business Media.

Ministry of Education of PRC. (2005). Statistical Report on the Implementation of the National Education Funds in 2004. [Online]. [Accessed December 31st]. Available from: http://www.moe.edu.cn/srcsite/A05 /s3040/200512/t20051230_78264.html

Ministry of Education of PRC. (2011). Statistical Report on the Implementation of the National Education Funds in 2010. [Online]. [Accessed December 31st]. Available from: http://www.moe.edu.cn/srcsite/A05 /s3040/201112/t20111223_128871.html

Ministry of Education of the People's Republic of China. (2015). China Education Monitoring and Evaluation Index System. [Online]. [Accessed August 18th]. Available from: http://www.moe.edu.cn/srcsite/A03 /s182/201509/t20150907_206014.html

Norman, P. D., \& Darlington-Pollock, F. (2018). The changing geography of deprivation in Great Britain: Exploiting small area census data, 1971 to 2011. In J. Stillwell (Ed.), The Routledge Handbook of Census Resources, Methods and Applications: Unlocking the UK 2011 Census. Abingdon: Routledge.

OECD. (2008). Handbook on Constructing Composite Indicators: Methodology and User Guide. Paris: OECD.

OECD. (2012). Equity and Quality in Education: Supporting Disadvantaged Students and Schools, OECD Publishing. https://doi.org/10.1787/9789264130852-en

Pan, A., Bosch, D., \& Ma, H. (2017). Assessing water poverty in China using holistic and dynamic principal component analysis. Social Indicators Research, 130(2), 537-561. 
Postiglione, G. A. (2009). Dislocated education: The case of Tibet. Comparative Education Review, 53(4), 483-512.

Postiglione, G. A., Jiao, B., \& Goldstein, M. C. (2011). Education in the Tibetan autonomous region: Policies and practices in rural and nomadic communities. In J. Ryan (Ed.), Education Reform in China: Changing Concepts, Contexts and Practces (pp. 92-110). New York: Routledge.

Qian, X., \& Smyth, R. (2008). Measuring regional inequality of education in China: Widening coast-inland gap or widening rural-urban gap? Journal of International Development, 20(2), 132-144.

Robeyns, I. (2005). The capability approach: A theoretical survey. Journal of Human Development, 6(1), 93-117.

Rodríguez-Pose, A., \& Ezcurra, R. (2009). Does decentralization matter for regional disparities? A crosscountry analysis. Journal of Economic Geography, 10(5), 619-644.

Saito, M. (2003). Amartya Sen's capability approach to education: A critical exploration. Journal of Philosophy of Education, 37(1), 17-33.

Sen, A. (1995). Inequality Reexamined. Oxford: Oxford University Press.

Sen, A. (2001). Development as Freedom. New York: Anchor Books.

Shindo, Y. (2010). The effect of education subsidies on regional economic growth and disparities in China. Economic Modelling, 27(5), 1061-1068.

Standing Committee of the National People's Congress. (2006a). Compulsory Education Law of PRC. Article 2.

Standing Committee of the National People's Congress. (2006b). Compulsory Education Law of PRC. Article 42, Article 44, Article 45.

Sun, M. (2010). Education system reform in China after 1978: Some practical implications. International Journal of Educational Management, 24(4), 314-329.

Sun, X. (2012). The national medium- and long-term educational reform and development guideline (201020). Chinese Education \& Society, 45(3), 9-22.

Terzi, L. (2007). The capability to be educated. In M. Walker \& E. Unterhalter (Eds.), Amartya Sen's Capability Approach and Social Justice in Education. New York: Palgrave Macmillan.

The State Council of China. (2010). National Medium- and Long-Term Educational Reform and Development Plan Outline [Online]. [Accessed July 29th]. Available from: http://www.gov.cn/jrzg/2010-07/29 /content_1667143.htm

Thomas, S. M., \& Peng, W. J. (2010). Methods to evaluate educational quality and improvement in China. In J. Ryan (Ed.), Education Reform in China: Changing Concepts, Contexts and Practices. London: Routledge.

Tomul, E. (2009). Measuring regional inequality of education in Turkey: An evaluation by Gini index. Procedia-Social and Behavioral Sciences, 1(1), 949-952.

Tsang, M. C. (1996). Financial reform of basic education in China. Economics of Education Review, 15(4), 423-444.

Tsang, M.C. (2000). Education and national development in China since 1949: Oscillating policies and enduring dilemmas. China Review. pp.579-618.

UNESCO. (2002). Education for All, Is the World on Track? Paris: UNESCO Publishing.

UNESCO. (2015). Education 2030 Incheon Declaration and Framework for Action. Paris: UNESCO Publishing.

Unger, J. (1984). Severing the links between school performance and careers: The experience of China's urban schools, 1968-1976. Comparative Education, 20(1), 93-102.

Vaughan, R. (2007). Measuring capabilities: An example from girls' schooling. In M. Walker \& E. Unterhalter (Eds.), Amartya Sen's Capability Approach and Social Justice in Education (pp. 109-130). New York: Palgrave Macmillan.

Vyas, S., \& Kumaranayake, L. (2006). Constructing socio-economic status indices: How to use principal components analysis. Health Policy and Planning, 21(6), 459-468.

Walker, M. (2005). Amartya Sen's capability approach and education. Educational Action Research, 13(1), $103-110$.

Walker, M., \& Unterhalter, E. (2007). The capability approach: Its potential for work in education. In M. Walker \& E. Unterhalter (Eds.), Amartya Sen's Capability Approach and Social Justice in Education (pp. 1-18). New York: Palgrave Macmillan.

Wang, W. (2014). Decomposing inequality in compulsory education finance in China: 1998-2008. Public Finance and Management, 14(4), 437-458.

Wei, Y. D. (1999). Regional inequality in China. Progress in Human Geography, 23(1), 49-59. 
Whitty, G. (1997). Creating quasi-markets in education: A review of recent research on parental choice and school autonomy in three countries. Review of Research in Education, 22, 3-47.

Wilkinson, R. G., \& Pickett, K. (2010). The Spirit Level: Why Equality is Better for Everyone. London: Penguin Books.

Xiang, L., Stillwell, J., Burns, L., Heppenstall, A., \& Norman, P. (2018). A geodemographic classification of sub-districts to identify education inequality in Central Beijing. Computers, Environment and Urban Systems, 70, 59-70.

Yang, D. T. (2002). What has caused regional inequality in China? China Economic Review, 13(4), 331-334.

Zhang, X., \& Kanbur, R. (2009). Spatial inequality in education and health care in China. In S. Fan, S. M. R. Kanbur, \& X. Zhang (Eds.), Regional Inequality in China: Trends, Explanations, and Policy Responses. London: Rouledge.

Zhang, G., Zhao, Y., Lei, J., Zhao, Y., \& Qiu, W. (2012). Policy changes and educational reforms in China: Decentralization and marketization. On the Horizon, 20(4), 313-323.

Zhu, M., \& Peyrache, A. (2017). The quality and efficiency of public service delivery in the UK and China. Regional Studies, 51(2), 285-296. 